\title{
ARQUEOBOTÂNICA DAS MADEIRAS DA ALAMEDA BRÜSTLEIN: ESTUDO DE CASO DE UM SÍTIO ARQUEOLÓGICO HISTÓRICO DE SANTA CATARINA
}

\author{
Julita Reynaud Rodrigues ${ }^{1}$ \\ João Carlos Ferreira de Melo Júnior²
}

\begin{abstract}
RESUMO
Escavações em sítios arqueológicos do período colonial revelam, além de objetos em metal, cerâmica, vidro e outras matérias-primas já industrializados, diversos vestígios vegetais. Interpretações destes vestígios ajudam a aclarar aspectos sobre o modo de vida das pessoas e sua relação com o mundo natural muitas vezes desconhecido ou diferente daquele vivenciado em seus territórios de origem. O presente trabalho teve como objetivo identificar madeiras recuperadas durante a escavação arqueológica da Alameda Brüstlein, sítio histórico colonial em Joinville, Santa Catarina. Secções transversais e longitudinais foram obtidas das amostras para produção de lâminas histológicas. A caracterização da madeira foi baseada na terminologia proposta pela IAWA - International Association of Wood Anatomists (1989). A determinação dos táxons se deu por meio de comparação em coleção de referência pertencente à xiloteca da Universidade da Região de Joinville (JOIw), banco de dados Inside Wood e literatura especializada. As principais madeiras identificadas foram a copaíba (Copaifera trapezifolia) a canela (Ocotea sp - Lauraceae), um recurso florestal de alta densidade básica, o que lhe confere grande resistência mecânica e elevada durabilidade quando exposta às condições do ambiente. É de ocorrência natural em ambientes florestais da Mata Atlântica. No sítio estudado, tal madeira foi encontrada na forma de tábuas de diferentes dimensões. Sua disposição no sítio sugere que tenham sido utilizadas passarelas e caminhos de passagem, uma vez que o sedimento das quadras escavadas compreende os típicos solos lodosos de manguezal. O resultado obtido reflete níveis de apropriação da natureza e seus recursos associados ao conhecimento das propriedades tecnológicas das madeiras e seu uso potencial.
\end{abstract}

Palavras-chave: Alameda Brüstlein, Anatomia da madeira, Arqueobotânica, Arqueologia histórica, Colônia Dona Francisca, Sítio histórico.

\footnotetext{
${ }^{1}$ Pós-graduação em Arqueologia da Univille.

2 Orientador, Laboratório de Anatomia e Ecologia Vegetal, Departamento de Ciências Biológicas, Universidade da Região de Joinville. E-mail: jcmelo_wood@hotmail.com.
} 


\section{INTRODUÇÃO}

A cidade de Joinville está inserida em uma paisagem entre a Serra do Mar e a Baía da Babitonga, onde se destacam ecossistemas florestais e o manguezal (CARELLI; BOING, 2012). Os imigrantes que chegaram em 1850 se impressionaram com a quantidade de mata e se espantaram com a real situação do lugar. Era evidente que a realidade não correspondia às propagandas de incentivo à vinda ao Brasil apresentadas na Europa (GUEDES et al., 2005; FICKER, 2008). Dentre as técnicas construtivas que aqui utilizaram para a construção de moradias foi a técnica de enxaimel, a qual tinha a madeira como base da estrutura da edificação e as paredes geralmente eram cobertas de barro (AMARANTH, 2007).

Além do cultivo de alimentos, uma das principais tarefas dos imigrantes era a de abrir picadas e caminhos que permitissem o desenvolvimento territorial da colônia (FUCKNER et al., 1992). No entanto, devido às condições naturais do lugar as pessoas estavam sujeitas aos mosquitos, borrachudos, bichos-de-pé e às serpentes, além das ulcerações de aclimatação nas pernas e nos braços. As chuvas fortes, o clima quente, a alta umidade e o os solos alagadiços do manguezal tornavam o ambiente hostil (HERKENHOFF, 1987).

Junto à sede administrativa da colônia, edificada por Frederico Brüstlein em 1867 e conhecida como Palácio dos Príncipes (FICKER, 2008), foi projetada uma alameda pelo plantio de 56 palmeiras imperiais (Roystonea oleracea (Jacq.) O. F. Cook. - Arecaceae) vindas do Rio de Janeiro em 1867 (HERKENHOFF, 1987). Até os dias atuais, a Alameda Brüstlein é considerada um importante ícone cultural da história de Joinville que, em 2012, passou por uma revitalização, com a reabertura do trânsito de pedestres e a colocação de tubulação de condição de água pluvial. Por se tratar de um sítio arqueológico histórico, a realização da obra de revitalização foi acompanhada escavações arqueológicas desenvolvidas pelo Museu Arqueológico de Sambaqui de Joinville (MASJ), com o intuito de garantir o resgate de artefatos encontrados durante as atividades.

Durante as intervenções foram recuperados diversos materiais como objetos em metal e vidro, louças e madeiras trabalhadas. Dentre as várias categorias de objetos 
recuperados as peças em madeira no formato de vigas, tábuas e dormentes se destacaram, sendo alvo do presente estudo arqueobotânico.

A arqueobotânica consiste no estudo de restos vegetais encontrados em sítios arqueológicos (SCHEEL-YBERT et al., 2005-2006). Entre seus objetivos está o de reconstruir o ambiente passado por meio da compreensão da aplicabilidade dos recursos vegetais, além de revelar os costumes adotados por certos grupos (CECCANTINI, 2001).

Na região de Joinville, estudos relacionados à arqueobotânica ainda são incipientes, principalmente quanto a sítios históricos. No entanto, seu avanço é importante ao passo que permite ampliar as análises e interpretações acerca do contexto arqueológico por meio dos testemunhos de origem vegetal recuperados nos sítios arqueológicos. Na região nordeste de Santa Catarina são pioneiros os estudos sobre madeiras históricas utilizadas em construções históricas durante o período colonial, assim como em objetos do cotidiano, mobiliário, meios de transporte e maquinários comuns à vida na colônia Dona Francisca (MELO Jr., 2011; MELO Jr., 2012a; MELO Jr., 2012b; MELO Jr.; BOEGER, 2015).

Neste contexto, o presente estudo tem como objetivo identificar as madeiras recuperadas durante a escavação arqueológica do sítio histórico Alameda Brüstlein, atribuindo-lhes significado funcional no contexto da paisagem da Colônia Dona Francisca.

\section{MATERIAL E MÉTODOS}

\section{Recuperação das madeiras arqueológicas}

Conforme o relatório de monitoramento e salvamento arqueológico realizado na Alameda Brüstlein, a escavação se concentrou nas laterais da Alameda por meio da abertura de quadras arqueológicas de $1 \mathrm{~m}$ x $1 \mathrm{~m}$, englobando uma área de 12,50 $\mathrm{m}^{2}$ (BANDEIRA, 2013). O trabalho arqueológico também foi acompanhado de pesquisas documentais, iconográficas, orais e bibliográficas. O material coletado foi acondicionado em saco plástico e devidamente identificado através de ficha específica e encaminhado para o Museu Arqueológico de Sambaqui de Joinville (MASJ) para posterior descrição e 
salvaguarda. Dentre os vestígios recuperados tiveram destaque as peças em madeira na forma de tábuas, vigas e sarrafos.

\section{Preparação, descrição anatômica e identificação das madeiras arqueológicas}

De cada vestígio em madeira recuperado na escavação, foram obtidos corpos de prova não superiores a $2 \mathrm{~cm}^{2}$. Os corpos de prova foram amolecidos por cozimento em água e glicerina para posterior seccionamento em micrótomo de deslize (FERREIRINHA, 1958). Cortes histológicos nas secções transversal, longitudinal tangencial e longitudinal radial foram clarificados em hipoclorito de sódio, lavados em água destilada, corados com azul de astra e safranina, desidratados em série etílica crescente (KRAUS; ARDUIN, 1997) e montados em resina sintética do tipo verniz vitral (PAIVA et al., 2006). As lâminas histológicas produzidas foram tombadas na coleção de referência da Xiloteca da Universidade da Região de Joinville (JOIw) (MELO Jr. et al., 2014). Elementos dissociados da madeira foram produzidos mediante imersão de fragmentos de madeira em solução de Franklin até a completa dissociação em estufa a $60^{\circ} \mathrm{C}$ (KRAUS; ARDUIN, 1997) para a biometria de caracteres da madeira importantes na diagnose das espécies.

A densidade básica da madeira foi determinada pelo método da balança hidrostática (FOELKEL et al., 1971). A densidade foi calculada por meio da seguinte fórmula $\mathrm{P}_{1} / \mathrm{P}_{3}-$ $\mathrm{P}_{2}$, onde: $\mathrm{D}=$ densidade, $\mathrm{P}_{1}=$ peso da madeira seca, $\mathrm{P}_{2}=$ peso da proveta cheia de água e $\mathrm{P}_{3}=$ peso da madeira imersa na proveta.

A descrição da anatomia foi baseada na terminologia sugerida pela IAWA (1989). Foram consultadas descrições e ilustrações de obras de referência (RECORD; HESS, 1943; METCALFE; CHALK,1950; DÉTIENNE; JACQUET, 1983; MANIERI; CHIMELO, 1989). A determinação taxonômica das amostras de madeira arqueológica foi baseada na descrição das estruturas anatômicas e na comparação destas em coleção de referência (Xiloteca JOIw) e banco de dados INSIDE WOOD (2010). 


\section{RESULTADOS E DISCUSSÃO}

\section{Anatomia das madeiras arqueológicas}

A integridade da estrutura anatômica das amostras permitiu a preparação histológica e a posterior identificação de 13 das 18 peças de madeira recuperadas na escavação arqueológica (Figura 1). Seis espécies de madeira foram identificadas. As características anatômicas que possibilitaram a distinção entre as madeiras empregadas em estruturas construtivas, assim como a respectiva determinação das espécies estão sumarizadas na Tabela 1.

De maneira geral, as características anatômicas observadas nas amostras das madeiras arqueológicas estudadas estão de acordo com o apresentado na literatura (RECORD; HESS, 1943; METCALFE; CHALK,1950; DÉTIENNE; JACQUET, 1983; MANIERI; CHIMELO, 1989), assim como na base de dados INSIDE WOOD (2010).

\section{Usos e aplicações das madeiras arqueológicas}

As madeiras identificadas pertencem a plantas de hábito arbóreo encontradas em formações florestais comuns na região nordeste do estado de Santa Catarina (MELO Jr.; BARTZ, 2009). Tais madeiras são atualmente consideradas matérias-primas de excelente qualidade em termos de uso em atividades humanas. Conforme Paula e Alves (2007), as principais aplicações das madeiras identificadas compreendem a carpintaria civil, vigamentos, esquadrias, escadas, tacos de assoalho, vagões, carroçarias e carpintaria geral para Aspidosperma sp. (peroba); objetos em áreas isoladas para Handroanthus heptaphyllus (ipê); construção civil, esquadrias, caixilhos e mobiliário para Ocotea-Nectandra (canela); construção civil e na confecção de móveis, vigas, caibros, ripas, rodapés, caixilhos e assoalhos para Terminalia triflora (amarelinho); função ornamental para Cassia sp.(chuvade-ouro); e marceria em geral, móveis e implementos agrícolas para Copaifera trapezifolia (copaíba). 
Do ponto de vista tecnológico a correta utilização das madeiras e sua aplicação estão atreladas às suas propriedades físicas e mecânicas, principalmente quando as madeiras são destinadas à construção civil em elementos construtivos que receberão grande carga de peso ou estarão mais expostos às intempéries. Dentre os índices que caracterizam a qualidade da madeira, destaca-se a densidade básica, propriedade física de grande variação entre as espécies florestais (VITAL, 1984).

As madeiras arqueológicas identificadas possuem densidade básica variando entre 0,5 e 0,97 $\mathrm{g} / \mathrm{cm}^{3}$ (Tabela 1), sendo consideradas madeiras moderadamente pesadas e pesadas (MAINIERE; CHIMELO, 1989). Este aspecto é tido como aquele que confere à madeira boa resistência mecânica e durabilidade em condições naturais (PAULA; ALVES, 2007), o que tem sido reportado como preferência de uso em diferentes períodos históricos e regiões brasileiras em se tratando do uso tecnológico da madeira (TEREZO, 2004; ANDREACCI; MELO Jr., 2011; MELO Jr.; BOEGER, 2015)

Considerando a elevada resistência mecânica apresentada pelas madeiras estudadas e os seus formatos de tábuas e vigas no contexto arqueológico, sugere-se que tais madeiras tenham sido utilizadas como caminhos para os colonos possibilitando sua mobilidade no território da colônia, uma vez que o substrato por ela ocupado é caracterizado como solos lodosos de manguezal em sua maior proporção.

Desta forma, é possível concluir que o emprego de madeiras de elevada densidade e resistência natural às intempéries constituíram, durante o período colonial de Joinville, uma importante fonte de matéria-prima para a produção de estruturas construtivas usadas como assoalhos para caminhos que permitiam o deslocamento das pessoas sobre o terreno, muito vezes lodoso, do território da colônia. 


\section{REFERÊNCIAS}

AMARANTH, E. Os mitos em torno da casa enxaimel. Joinville, ago. 2007. Disponível em: <http://redebonja.cbj.g12.br/ielusc/revi2005/revimodreg.php? id=4629>. Acesso em: 30 mar. 2014.

ANDREACCI, F.; MELO JR., J. C. F. Madeiras históricas do barroco mineiro: interfaces entre o patrimônio cultural material e a anatomia vegetal. Rodriguesia, v. 62, n. 2, p. 1 -11, 2011.

BANDEIRA, D. da R. Relatório de monitoramento e salvamento arqueológico da Alameda Brüstlein, Joinville/SC. Joinville: Fundação Cultural de Joinville, 2013.

CARELLI, M. N.; BOING, E. M. Patrimônio ambiental e cultural: a paisagem cultural de Joinville (SC) e suas modificações geradas pelo desenvolvimento. In: LAMAS, N. de C.; JAHN, A. R. M. Arte e cultura: passos, espaços e territórios. Joinville: Editora UNIVILLE, 2012. p. 295-311.

CECCANTINI, G. O uso de indicadores florísticos e faunísticos em arqueologia. Caderno de Pesquisa série Biologia, Santa Cruz do Sul, v. 13, n. 1, p. 47-56, jan/dez. 2001.

DÉTIENNE, P.; JACQUET, P. Atlas d'identification des bois de l'Amazonie et des régions voisines. França: Centre Téchnique Forestier Tropical, 1983. 640 p.

FERREIRINHA, M. P. Elementos de anatomia de madeiras folhosas portuguesas. Memórias da Junta de Investigação do Ultramar, Lisboa, 3, segunda série, 1958.

FICKER, C. História de Joinville: crônica da Colônia Dona Francisca. Joinville: Letradágua, 2008.

FOELKEL, C. E. B.; BRASIL, M. A. M.; BARRICHELO, L. E. G. Métodos para determinação da densidade básica de carvões para coníferas e folhosas. IPEF, v. 2/3, p. 6574, 1971.

FUCKNER, I. et al. História dos bairros de Joinville. Joinville: Arquivo Histórico, 1992.

GUEDES, S. P. L. de C. et al. Histórias de (I)migrantes: o cotidiano de uma cidade. 2. ed. Joinville: Editora UNIVILLE, 2005.

HERKENHOFF, E. Era uma vez um simples caminho... Fragmentos da história de Joinville. Joinville: Prefeitura de Joinville, Fundação Cultural de Joinville e Arquivo Histórico de Joinville, 1987. 
IAWA COMMITTEE. List of microscopic features for hardwood identification. IAWA Bulletin, v. 10, p. 220-332, 1989.

INSIDE WOOD. The inside wood. 2010. Disponível em: <database.http://www.insidewood.lib.ncsu.edu>. Acesso em: jan. 2011.

KRAUS, J. E.; ARDUIN, M. Manual básico de métodos em morfologia vegetal. Seropédica: Edur, 1997.

MAINIERI, C.; CHIMELO, J. P. Fichas de características das madeiras brasileiras. 2. ed. São Paulo: IPT, 1989.

MELO JR., J. C. F.; BOEGER, M. R. T. The use of wood in cultural objects in 19th Century Southern Brazil. IAWA Journal, v. 36, n. 1, p. 98-116, 2015.

MELO JR., J. C. F.; BARTZ, M. C. Análise florística e estrutural de remanescentes de mata atlântica do nordeste de Santa Catarina, Brasil. Revista Univille, v. 14, p. 41-56, 2009.

MELO JR., J. C. F. Aspectos anatômicos de madeiras históricas do período colonial do nordeste de Santa Catarina: elementos para conservação do patrimônio cultural. Revista Confluências Culturais, v. 1, p. 70-84, jul. 2012a.

Anatomia de madeiras históricas: um olhar biológico sobre o patrimônio cultural. Joinville: Editora UNIVILLE, 2012b.

Patrimônio em madeira: saberes tradicionais e arquitetura vegetal como subsídio à conservação da cultura material. Revista Museu, v. 1, p. 1-4, 2011.

; AMORIM, M. W.; SILVEIRA, E. R. A xiloteca (coleção Joinvillea - JOIw) da Universidade da Região de Joinville. Rodriguésia, v. 65, p. 1.057-1.060, 2014.

METCALFE, C. R.; CHALK, L. Anatomy of the dicotyledons. Oxford: Claredon Press, 1950.

PAIVA, J. G. A. et al. Verniz vitral incolor 500: uma alternativa de meio de montagem economicamente viável. Acta Botanica Brasilica, v. 20, n. 2, p. 257-264, 2006.

PAULA, J. E.; ALVEZ, J. L. H. 897 madeiras nativas do Brasil: anatomia-dendrologia, dendrometria-produção-uso. Porto Alegre: Cinco Continentes, 2007. 438 p.

RECORD, S. J.; HESS, R. W. Timbers of new world. New Haven: Yale University Press, 1943. 
SCHEEL-YBERT, R. et al. Proposta de amostragem padronizada para macro-vestígios bioarqueológicos: antracologia, arqueobotânica, zooarqueologia. Revista do Museu de Arqueologia e Etnologia, São Paulo, v. 15-16, 2005-2006.

TEREZO, R. F. Propriedades mecânicas de madeiras utilizadas em estruturas históricas e contemporâneas estimadas por meio de ultra-som. Dissertação. 120 f. (Mestrado em Engenharia Civil) - Universidade Federal de Santa Catarina, Florianópolis, 2004.

VITAL, B. R. Métodos de determinação da densidade da madeira. Viçosa: Sociedade de Investigações Florestais, 1984. 21 p. (Boletim técnico 1). 
Tabela 1. Características anatômicas de diagnose das madeiras arqueológicas da Alameda Brüstlein, densidade básica e sua correspondência taxonômica.

\begin{tabular}{|c|c|c|c|c|c|c|}
\hline Família & 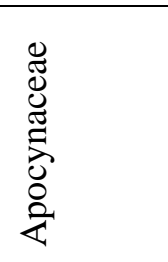 & 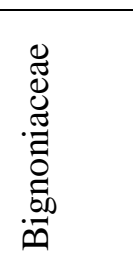 & 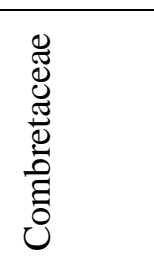 & 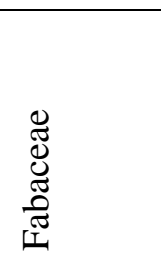 & 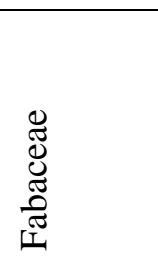 & 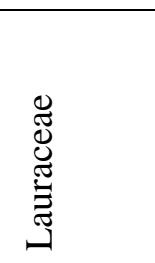 \\
\hline Espécie & 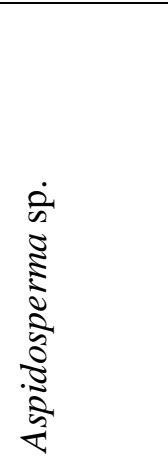 & 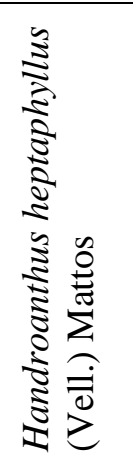 & 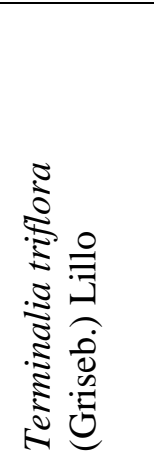 & 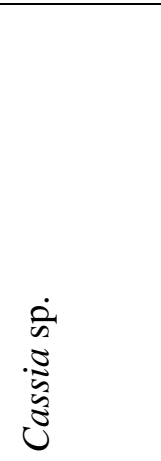 & 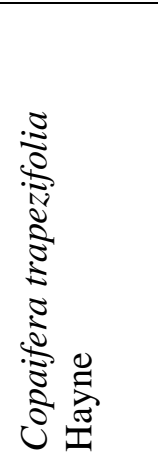 & $\begin{array}{l}0 \\
0 \\
0 \\
0 \\
0 \\
0 \\
z \\
1 \\
0 \\
0 \\
0 \\
0 \\
0\end{array}$ \\
\hline Nome popular & peroba & ipê & $\begin{array}{l}\text { lança- } \\
\text { amarela }\end{array}$ & $\begin{array}{l}\text { chuva- } \\
\text { de-ouro }\end{array}$ & copaíba & canela \\
\hline Amostra & 622,666 & 672 & 417 & $\begin{array}{l}659,660 \\
664,670 \\
671\end{array}$ & 673 & $\begin{array}{l}662,663 \\
665\end{array}$ \\
\hline Camadas de crescimento & + & + & & + & + & + \\
\hline Porosidade difusa & + & + & + & + & + & + \\
\hline Vasos exclusivamente solitários & + & + & & + & + & + \\
\hline Vasos múltiplos & & raro & + & + & & + \\
\hline Arranjo difuso & + & + & + & + & + & + \\
\hline Freqüência $\left(\right.$ vasos $\left./ \mathrm{mm}^{2}\right)$ & $40-100$ & $5-20$ & $<5$ & $<5$ & $5-20$ & $5-20$ \\
\hline Diâmetro tangencial dos vasos $(\mu \mathrm{m})$ & $50-100$ & $50-100$ & $100-200$ & $>200$ & $100-200$ & $50-100$ \\
\hline Comprimento do vaso $(\mu \mathrm{m})$ & $390-810$ & $53-130$ & $260-440$ & $210-310$ & $230-370$ & $390-640$ \\
\hline Tilose & & & & & & $\begin{array}{l}+ \\
+\end{array}$ \\
\hline $\begin{array}{l}\text { Placa de perfuração simples } \\
\text { Pontuacão intervascular alterna }\end{array}$ & $\begin{array}{l}+ \\
+\end{array}$ & $\begin{array}{l}+ \\
+\end{array}$ & $\begin{array}{l}+ \\
+\end{array}$ & $\begin{array}{l}+ \\
+\end{array}$ & $\begin{array}{l}+ \\
+\end{array}$ & $\begin{array}{l}+ \\
+\end{array}$ \\
\hline Pontoação intervascular guarnecida & & & & & + & \\
\hline $\begin{array}{l}\text { Pontoação intervascular diminuta }(<4 \\
\mu \mathrm{m})\end{array}$ & + & & & & + & \\
\hline $\begin{array}{l}\text { Pontoação intervascular média (7-10 } \\
\mu \mathrm{m})\end{array}$ & & & + & & & \\
\hline $\begin{array}{l}\text { Pontoação intervascular grande (>10 } \\
\mu \mathrm{m})\end{array}$ & & + & & + & & + \\
\hline $\begin{array}{l}\text { Pontoação raio-vascular similar a } \\
\text { intervascular }\end{array}$ & + & + & + & + & + & \\
\hline $\begin{array}{l}\text { Pontoação raio-vascular de borda } \\
\text { reduzida }\end{array}$ & & & & & & + \\
\hline Traqueíde vasicêntrica & + & & & & & \\
\hline Fibras septadas & & & & + & & + \\
\hline Fibras com paredes delgadas a & + & + & + & & + & + \\
\hline
\end{tabular}


espessas

Fibras com paredes espessas

Parênquima apotraqueal difuso

Parênquima apotraqueal difuso em agregados

Parênquima paratraqueal escasso

Parênquima paratraqueal vasicêntrico

Parênquima paratraqueal aliforme

Parênquima paratraqueal confluente

Parênquima paratraqueal unilateral

Parênquima marginal

Série fusiforme do parênquima axial

Raios exclusivamente unisseriados

Raios de 1-3 células de largura

Raios $>4$ células de largura

Raios agregados

Raios com apenas células
procumbentes

Raios com células procumbentes no

corpo e 1 fileira de eretas e/ou quadradas marginais

Raios com células procumbentes no

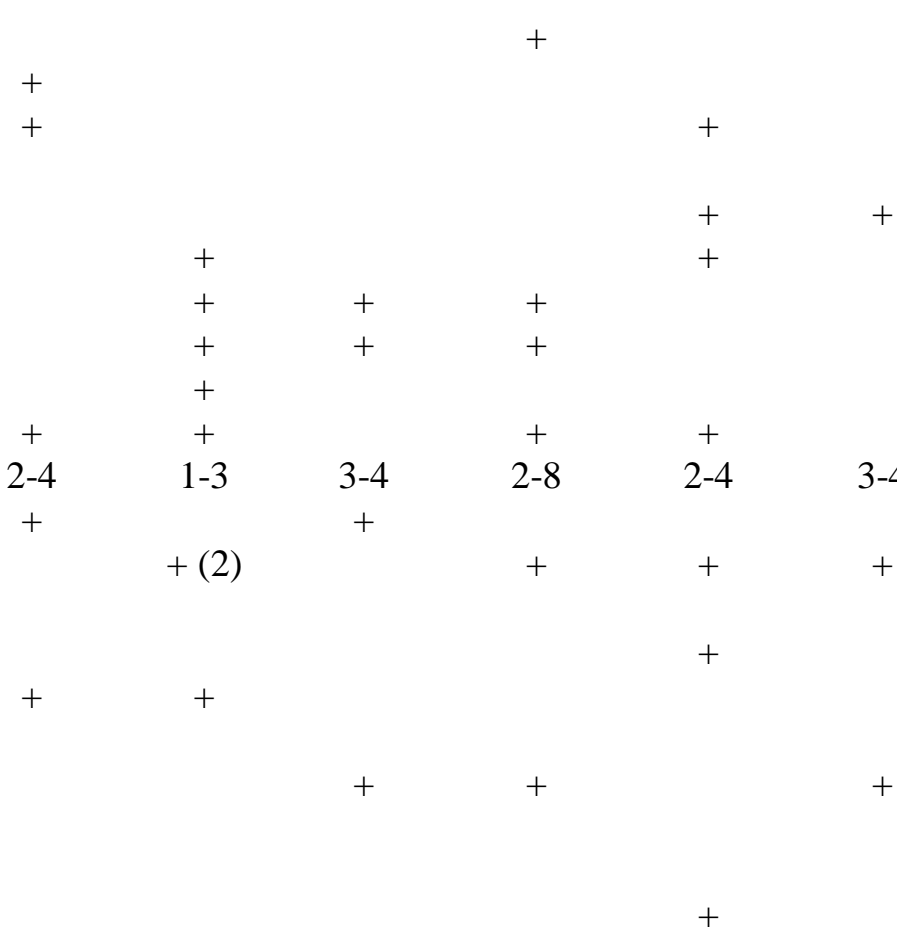

corpo e 2 a 4 fileiras de eretas e/ou quadradas marginais

Altura dos raios ( ${ }^{\circ}$ células)

Freqüência dos raios $(\mathrm{n} / \mathrm{mm})$

Parênquima axial e/ou vasos

estratificados

Cristais prismáticos

Células oleíferas

Canais intercelulares de origem traumática

Depósitos de gomas/resinas Densidade básica da madeira $\left(\mathrm{g} / \mathrm{cm}^{3}\right)$ 
Revista Tecnologia e Ambiente, Dossiê IX Reunião da Sociedade de Arqueologia Brasileira / Regional Sul, v. 21, n. 1, 2015, Criciúma, Santa Catarina. ISSN 1413-8131

Figura 1. Aspecto geral de algumas peças em madeira recuperadas na escavação arqueológica da Alameda Brüstlein. A: Aspidoserma sp. B: Handroanthus heptaphyllus.C: Terminalia triflora. D: Cassia sp. E: Copaifera trapezifolia. F: Ocotea-Nectandra. A, C e D: forma de vigas ou dormentes. B, E e F: forma de tábuas.

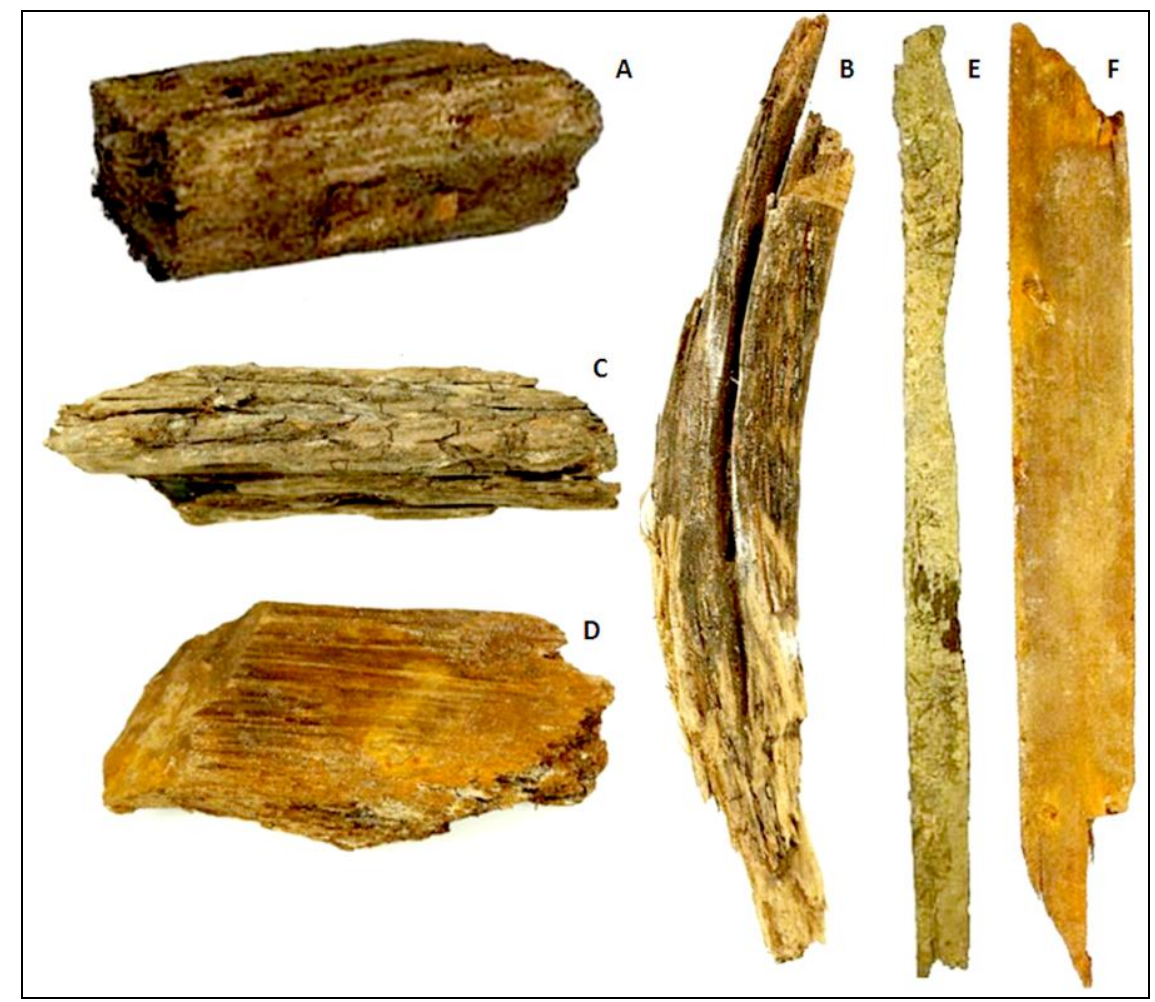

Fonte: dos autores. 